Letter

\title{
Preoperative Serum and Intra-platelet Serotonin in Prognosis: Useful or Useless?
}

\author{
Qinling Yang ${ }^{1 *}$, Sushun $\mathrm{Liu}^{2 *}$, Chaoling Deng², Bo Shu², Jingyao Zhang1, Mimi Zhai ${ }^{\circledR}$ \\ 1. Department of Hepatobiliary Surgery, the First Affiliated Hospital of Xi' an Jiaotong University, Xi'an, Shaanxi 710061, China \\ 2. Department of General Surgery, the Second Xiangya Hospital, Central South University, Changsha, Hunan 410011, China \\ ${ }^{*}$ Qinling Yang and Sushun Liu contributed equally to this article. \\ $\triangle$ Corresponding author: Mimi Zhai, MPH, Department of Hepatobiliary Surgery, The First Affiliated Hospital of Xi'an Jiaotong University, No. 277 West \\ Yan-ta Road, Xi'an 710061, Shaanxi Province, China. 330925531@qq.com; Telephone: +86-29-85323900 Fax: +86-29-85324642 \\ (c) Ivyspring International Publisher. This is an open access article distributed under the terms of the Creative Commons Attribution (CC BY-NC) license \\ (https://creativecommons.org/licenses/by-nc/4.0/). See http://ivyspring.com/terms for full terms and conditions.
}

Received: 2018.05.27; Accepted: 2018.07.25; Published: 2018.09.08

We read the recent Journal of Cancer article published by Aryal et al with great interest [1]. The author demonstrated that lower serum and intra-platelet (IP) 5-HT were closely related with higher recurrence rate after four weeks of operation. Additionally, serum and IP 5-HT could be used as the independent factors to predict the recurrence of hepatocellular carcinoma. However, the preoperative serum and IP 5-HT did not affect the recurrence in their study. The serum and IP 5-HT were even higher in non-recurrence patients before operation.

We want to point out in contrary to the results which obtained by Aryal et al. High serum and IP 5-HT before liver resection both were closely related with poor prognosis including poor overall survival and poor recurrence -free survival. A study conducted by us demonstrated that high serum 5-HT, high IP 5-TH and high IP 5-HT per platelet were all associated with poor overall survival and recurrence-free survival via survival analysis among 113 HCC patients [2]. Additionally, Padickakudy et al study also indicated that patients with excessively high IP 5 -HT $(>134 \mathrm{ng} / \mathrm{ml})$ suffered an earlier recurrence [3] . A study conducted by Xia et al found that a preoperative elevated 5-HT was related with advanced tumor node metastasis and poor recurrence-free survival and overall survival via multivariate analysis [4]. Additionally, high 5-HT was proved to be a marker for predicting the recurrence of breast cancer by Frobe et al [5]. The peripheral 5-HT was mainly restored in the dense granules of platelets and was released after platelet activation. Thus, studies exploring the relationship between platelet and cancer recurrence could indirectly indicated the effects of 5-HT on cancer recurrence. Lee et al study showed that pretreatment platelet count was closely associated with extrahepatic metastasis of liver cancer and the Pang et al letter proposed that the platelet affected on extrahepatic metastasis of via platelet-derived serotonin [6, 7]. Additionally, our previous study demonstrated that platelet count had the ability to predict postoperative recurrence of hepatocellular carcinoma [8].

Moreover, 5-HT was proved to promote proliferation of hepatoma cell via basic research. Our previous study found that 5-HT promoted hepatoma cell proliferation via 5-HT-5-HT ${ }_{2 B} R-p E R K-Y a p$ axis [9]. Besides, studies conducted by Soll et al and Liang et al were proved the serum-like and promotion effect of 5-HT on hepatoma cell [10-12].

In conclusion, the preoperative level of 5-HT and IP 5-HT were higher in HCC patients. Furtherly, higher 5-HT and IP 5-HT level before treatment were both closely associated with poorer overall survival and recurrence-free survival. Thereby, 5-HT might be a potential therapeutic target. Because of the discrepancy with Aryal's results, more clinical researchers are needed to explore the level and effect of 5-HT and IP 5-HT on prognosis of HCC patients.

\section{References}

1. Aryal B, Shimizu T, Kadono J, et al. Post-Resection Exhaustion of Intra-Platelet Serotonin: Also an Indicator of Early Hepatocellular Carcinoma Recurrence? J Cancer. 2017;8(19):3984-91.

2. Shu B, Wang S, Deng Y, et al. Intra-platelet serotonin in prognosis of tumorigenesis: Friend or foe? Journal of hepatology. 2018;68(6):1333-4. 
3. Padickakudy R, Pereyra D, Offensperger F, et al. Bivalent role of intra-platelet serotonin in liver regeneration and tumor recurrence in humans. Journal of hepatology. 2017;67(6):1243-52.

4. Xia Y, Wang D, Zhang $\mathrm{N}$, et al. Plasma serotonin level is a predictor for recurrence and poor prognosis in colorectal cancer patients. J Clin Lab Anal. 2018;32(2).

5. Frobe A, Cicin-Sain L, Jones G, et al. Plasma free serotonin as a marker for early detection of breast cancer recurrence. Anticancer Res. 2014;34(3):1167-9.

6. Lee $\mathrm{CH}$, Lin $\mathrm{YJ}$, Lin $\mathrm{CC}$, et al. Pretreatment platelet count early predicts extrahepatic metastasis of human hepatoma. Liver international : official journal of the International Association for the Study of the Liver. 2015;35(10):2327-36.

7. Pang Q, Liu C, Qu K, et al. Conflicting relationship between platelets and prognosis of hepatocellular carcinoma: is platelet-derived serotonin involved in? Liver international : official journal of the International Association for the Study of the Liver. 2015;35(11):2484.

8. Pang $\mathrm{Q}$, Zhang JY, Xu XS, et al. Significance of platelet count and platelet-based models for hepatocellular carcinoma recurrence. World journal of gastroenterology : WJG. 2015;21(18):5607-21.

9. Liu S, Miao R, Zhai M, et al. Effects and related mechanisms of serotonin on malignant biological behavior of hepatocellular carcinoma via regulation of Yap. Oncotarget. 2017;8(29):47412-24.

10. Soll C, Riener MO, Oberkofler CE, et al. Expression of serotonin receptors in human hepatocellular cancer. Clinical cancer research : an official journal of the American Association for Cancer Research. 2012;18(21):5902-10.

11. Soll C, Jang JH, Riener MO, et al. Serotonin promotes tumor growth in human hepatocellular cancer. Hepatology. 2010;51(4):1244-54.

12. Liang $\mathrm{C}$, Chen $\mathrm{W}$, Zhi $\mathrm{X}$, et al. Serotonin promotes the proliferation of serum-deprived hepatocellular carcinoma cells via upregulation of FOXO3a. Molecular cancer. 2013;12:14 
